ROCZNIKI HUMANISTYCZNE

Tom LXVIII, zeszyt $10 \quad-\quad 2020$

DOI: http://dx.doi.org/10.18290/rh206810-16

OLGA MAKAROWSKA

\title{
ОРИЕНТАЦИЯ НА СЕТЕВОСТЬ В ЛИНГВОДИДАКТИЧЕСКОМ ДИСКУРСЕ
}

\section{ВСТУПЛЕНИЕ}

Обсуждая проблемы обучения иностранным языкам представителей новых поколений, лингводидакты единодушно признают необходимость инновационного обновления лингводидактического дискурса (ЛДД). Цель статьи - рассмотреть ориентацию на сетевость (ОС) как одну из инноваций, призванных усовершенствовать обучение РКИ. Основные задачи - выявление особенностей сетевости в лингводидактическом преломлении, их поуровневое описание и представление предложений по внедрению ОС в практику обучения РКИ польских студентов ${ }^{1}$. Основной метод исследования - анализ научной и научно-методической литературы, вспомогательный - группировка. Теоретическую основу составляют работы, занимающиеся изучением особенностей «цифровой» молодежи и проблемами ее обучения.

К.фил.н. ОльгА МАКАРОвскА - Университет Адама Мицкевича в Познани, Институт русской и украинской филологии, Кафедра литературно-культурной компаративистики; адрес для почтовых отправлений: Instytut Filologii Rosyjskiej i Ukraińskiej, al. Niepodległości 4, 61-874 Poznań; e-mail: filin@wp.pl. ORCID: https://orcid.org/0000-0002-3687-7993.

Dr Olga Makarowska - Uniwersytet Adama Mickiewicza w Poznaniu, Instytut Filologii Rosyjskiej i Ukraińskiej, Zakład Komparatystyki Literacko-Kulturowej; adres do korespondencji: Instytut Filologii Rosyjskiej i Ukraińskiej, al. Niepodległości 4, 61-874 Poznań; e-mail: filin@wp.pl. ORCID: https://orcid.org/0000-0002-3687-7993.

Olga MaKarowska, PhD - Adam Mickiewicz University in Poznań, Institute of Russian and Ukrainian Philology, Department of Comparative Literary and Cultural Studies; address for correspondence: Instytut Filologii Rosyjskiej i Ukraińskiej, al. Niepodległości 4, 61-874 Poznań; email: filin@wp.pl. ORCID: https://orcid.org/0000-0002-3687-7993.

${ }^{1}$ Привлечение работ зарубежных ученых, изучающих особенности «цифровых аборигенов» (название Марка Пренски) своих этносоциумов, вызывает вопрос: «Справедливы ли их выводы по отношению к польским „детям Сети”?». Утвердительный ответ позволяет дать, среди прочего, концепция «глобального подростка» (на тему см.: Melosik, 2003: 26-27). 


\section{2. ЛИНГВОДИДАКТИЧЕСКИЙ ДИСКУРС}

В работах польских и российских лингводидактов понятие ЛДД не получило общепринятого определения ${ }^{2}$. Это объясняется: невысокой востребованностью термина в сравнении с педагогическим, образовательным и дидактическим дискурсом; размытостью понятия дискурс, не имеющего однозначного толкования во многих областях гуманитарного знания (Skudrzyk \& Warchala 272); разногласием среди специалистов по поводу применения термина, относящих его к обучению и родному и иностранному языку.

В целом подходы польских и российских ученых к трактовке ЛДД схожи. Он связывается с научными текстами, посвященными вопросам обучения иностранным языкам, или с педагогическим общением, где на первый план выдвигаются основные аспекты дискурса, т. е. познавательные процессы, использование языка и интеракции (van Dijk 42).

Исходя из понимания глоттодидактики (Wilczyńska \& MichońskaStadnik 29) и дискурса (Grzmil-Tylutki 271), ЛДД можно определить как вид деятельности, осуществляемой в лингводидактическом образовательном пространстве во всей его физической и психической комплексности и протяженности, в т. ч. внеаудиторной, и охватывающей процесс (об)учения, социально-языковую активность, коммуникативные практики и результаты этой деятельности. Формы реализации ЛДД: нефиксированная типа коммуникативного взаимодействия на занятиях; фиксированная на любом носителе; смешанная, напр., написанный и реализованный сценарий урока.

Главные компоненты ЛДД - составляющие известной глоттодидактической модели Францишека Гручи, т.е. учащийся, преподаватель, канал коммуникативного взаимодействия. Именно их прежде всего касаются инновации, вводимые в лингводидактический процесс.

\footnotetext{
${ }^{2}$ В польской терминологии используется определение глоттодидактический (Gajda 25). Глоттодидактика означает «обучение языку» (Pfeiffer 13), но сама дисциплина «больше ориентирована на обучение иностранным языкам» (Gajda 25). Понятие глоттодактический дискурс не всегда уточняется (см. работы Гражины Зажицкой). Здесь и далее перевод наш - O.M.
} 


\section{2. ЛИНГВОДИДАКТИЧЕСКИЕ ИННОВАЦИИ}

Инновация в лингводидактике связывается с новшеством, повышающим качество обучения. Признаки инноваций, их типология, классификация, содержание, характеристики, подходы и методы инновационного обучения подробно описаны учеными (Dudel et al.; Such; Lysakova/ Лысакова; Kashina/Кашина; Ikhsangaliyeva \& Nurzhanova/Ихсангалиева и Нуржанова).

Инновации охватывают явные нововведения, касающиеся технических, управленческих, организационных, коммуникативных и пр. аспектов образования и обучения, и способы мышления (Dudel et al. 52). Последние обусловлены инновативностью мышления, предполагающей открытость новым идеям, предложениям в области познания, объяснения и описания мира, что требует, как и адекватное образование, постоянной готовности «отказываться от привычных навыков мышления, подвергать сомнению собственные „концептуальные схемы” (Melosik 19).

Инновационное мышление относительно обучения иностранным языкам «цифровой» молодежи видится не столько в осознании проблемы, сколько в реальном пересмотре взглядов на нее, сопряженном с поиском путей решения и проверки их правильности.

При реализации этой задачи обоснованно отталкиваться от признаков, отличающих «цифровые» поколения от «аналоговых». Наиболее яркие из них - клиповость мышления ${ }^{3}$ и сетевость. Поскольку первая подробно описана в ряде работ, остановимся на сетевости как на свойстве именно субъекта ${ }^{4}$.

\section{3. ПОНЯТИЕ СЕТЕВОСТИ}

Сетевость есть результат вовлеченности индивида в интернет-пространство с целью осуществления определенных видов деятельности,

\footnotetext{
${ }^{3}$ Сетевое мышление, «умение замечать взаимосвязи между факторами и их анализирование» (Piekarczyk 511), не затрагиваем, ибо трактуется учеными как компетенция, чье формирование требует овладения специальными знаниями и умениями. Клиповое же мышление, не будучи врожденной особенностью (обратное не доказано), приобретается естественным путем, а не в ходе тренингов.

${ }^{4}$ Сетевость еще понимается как: а) сеть корреляций между частями динамической системы или между частями и целым (Piekarczyk \& Zimniewicz 46); б) возможность использования Сети в определенных целях (Osipova/Осипова 214).
} 
действий, участия в интеракциях. Иначе говоря, сетевость - это опыт коммуникативных и социальных практик, а также разнообразных, реализуемых посредством Сети взаимоотношений, (интер)акций и действий, переносимый из виртуальной действительности в реальную. Сетевостью объясняется то, что представители новых генераций «не замечают границы между „быть offline” и „быть online” (Karwatowska \& Jarosz 55).

Сетевость раскрывается в действии, причем одни и те же черты индивидов, отмеченные беспрецедентной амбивалентностью (Nosova/Hocoва 55), как форма ее объективации, часто несут позитивный и негативный потенциал одновременно. Например, многозадачность позволяет выполнять несколько заданий параллельно, но сопровождается более поверхностной и менее эффективной обработкой информации (Spitzer 204).

Сетевость заметно влияет на организацию деятельности, (взаимо) действий и взаимоотношений молодежи в повседневной жизни и в процессе институционального обучения, в т. ч. иностранным языкам. Поэтому ОС в ЛДД, наряду с учетом клиповости мышления, относим к одному из факторов успешности овладения РКИ. Рассмотрим ОС как форму лингводидактической инновации.

\section{4. ОРИЕНТАЦИЯ НА СЕТЕВОСТЬ}

\section{1 ТЕОРЕТИЧЕСКАЯ БАЗА}

Ввиду отсутствия теорий ${ }^{5}$ относительно обучения «цифровой» молодежи иностранным языкам, теоретической базой внедрения ОС в ЛДД может послужить концепция маскирования (Makarovska/Макаровска) и факторы обучения «детей Сети» Дона Тапскотта (Tapscott 139-141, 216-259):

- ориентация системы образования и процесса обучения на учащегося, а не на преподавателя;

- сотрудничество преподавателей с учащимися, оказание помощи в процессе самостоятельного открытия ими мира;

- переход от однонаправленного обучения к интерактивному;

- ориентация на совместную деятельность при одновременной направленности на индивидуализацию обучения, что обусловлено

\footnotetext{
${ }^{5}$ Коннективизм, предлагающий использовать сеть, узлами которой является что угодно от сведений до чувств, сосредоточиваясь на работе с информацией (Polak), не касается сетевости как признака обучаемых.
} 
сочетанием желания молодежи проявлять индивидуальность со стремлением к «стадности» (Nosova/Носова 62);

- применение современных технологий;

- учет основных качеств «цифровой» молодежи - стремления к свободе, к удовлетворению своих потребностей, к наблюдению, честности, сотрудничеству, развлечению и поддержанию высокого темпа.

ОС предполагает не усиление сетевости, а ее учет при выстраивании лингводидактической деятельности, нацеленной на повышение качества обучения.

\section{2 ОРИЕНТАЦИЯ НА СЕТЕВОСТЬ КАК ИННОВАЦИЯ}

Причисление ОС к инновациям обусловлено наличием у нее всех основных инновационных признаков, первый из которых целенаправленность $^{6}$. Главная цель применения ОС - содействие выравниванию дисбаланса, возникающего из-за преобладания методов, не предназначенных для обучения «цифровых» учащихся (подробнее см.: Makarovska/Макаровска 123-127). Ее реализация призвана повысить успешность усвоения РКИ, мотивацию и активность обучаемых, а также укрепить социальные связи между ними.

Второй признак - запланированность, т. е. продуманность организации и последовательность внедрения.

Третий - организованность, подразумевающая наличие человеческих ресурсов, способных к развитию, и средств осуществления инновации (приемов и технологий, в т. ч. информационно-коммуникационных).

Четвертый - контролируемость, напр., мониторинг успеваемости учащихся до и после внедрения ОС, их активности, инициативности и мотивации путем наблюдения, анкетирования, интервьюирования (по выбору/комплексно).

Согласно критериям (Olszewska 42), ОС относится к инновациям методическим, технологическим и организационным на уровне языковой группы, ибо связана с изменениями, охватывающими способы и технологические средства обучения, а также организацию совместной работы и коммуникации в ЛДД. Вносимые изменения принадлежат

\footnotetext{
${ }^{6}$ Определение признаков дано по Катажине Ольшевской, описавшей их со ссылкой на работу Крыстыны Витек (Olszewska 41).
} 
к категории «приспособление», чья суть - в придании действиям адекватного характера, соответствующего актуальному положению дел, что обусловливает не пионерскую, а ассимиляционную степень креативности инновации (Olszewska 43).

Источником ОС «есть все, что является результатом собственного педагогического опыта», прошедшего качественные преобразования (Olszewska 44). Форма ОС как инновации - модернизация, направленная на осовременивание и придание привлекательности процессу обучения (Olszewska 44) РКИ.

Ввиду многоуровневости характера ОС целесообразно ее применение на всех уровнях.

\section{5. ОРИЕНТАЦИЯ НА СЕТЕВОСТЬ: ОРГАНИЗАЦИОННЫЙ УРОВЕНЬ}

Сеть, состоящая из узлов и связей между ними, противопоставлена иерархическим структурам, организованным по схеме иентр - периферия (Kreft 759). Поэтому важно и включение в сеть, и исключение из нее, являющееся процессом двусторонним, ибо исключенные «отторгают логику структурного доминирования и социального отторжения» (Castells 40). Это обусловливает: 1) легкость смены сетей, сопряженную со свободой выбора, которая для «цифровой» молодежи есть нечто очевидное и естественное (Łaszyn); 2) установление разнонаправленных (не)регулярных, (не)векторных, (не)постоянных коммуникативных связей и контактов; 3) важность координации действий в сетевой группе с учетом позиции в ней участников (Ratajczak-Mrozek 18); 4) ориентация на диалог и включенность в информационный процесс, позволяющую влиять на поступающие данные, т. е. прерывать и моделировать поток информации и ее форму, напр., «смешивая текст, звук, изображение и графику» (Łaszyn); 5) стремление делиться впечатлениями, эмоциями, сведениями, материалами и ценностями (Filiciak et al. 76-80).

Налицо необходимость пересмотра подхода к трактовке языковой группы и позиции преподавателя по отношению к ней вообще и организации работы учащихся в частности. Отсюда, обоснованным представляется преобразование группы в сетевое сообщество путем маскирования ${ }^{7}$. Это позволит сохранить иерархические отношения на линии

\footnotetext{
${ }^{7}$ Преобразование без маскирования на когнитивном уровне грозит навязыванием уча-
} 
учащиеся - преподаватель и создать комфортные условия эффективного обучения РКИ с помощью простых приемов и способов, как то:

1. Создание общей сетевой среды реализации ЛДД, включающей (вне)вузовское пространство, что облегчает налаживание связей между учащимися в аудитории и препятствует их обрыву вне ее ${ }^{8}$. Этому содействуют групповые формы работы, в т. ч. при организации внеаудиторной учебной деятельности, где преобладают индивидуальные задания. Выполнение групповых (домашних) заданий требует объединения усилий, координации и синхронизации совместных действий. Учащиеся вынуждены контактироваться, поддерживать акцептабельный диалог и «отвечать за работу свою и группы» (Latoch-Zielińska 46). Этому помогут брейнсторминг, метод (телекоммуникационных) проектов, творческие веб-квесты, драматизация, техники типа контраргументация аргументация, групповой опрос и пр.

2. Сменный состав групп, выполняющих (вне)аудиторные задания. Он устанавливается студентами или вместе с преподавателем, что не ограничивает чувства свободы выбора и позволяет разнообразить контакты между учащимися.

3. Включенность в сеть преподавателя с сохранением иерархической позиции. Имеются в виду: использование/размещение учебных подкастов; создание виртуальных классов/мини-курсов, скажем, с помощью интерактивной платформы Google Classroom; или как минимум контакты с учащимися через и-мейл, напр., высылание домашних заданий и пр. (коммуникация же через соцсети способствует стиранию иерархических границ, переводя преподавателя в ранг модератора) и т. п.

4. Предоставление студентам возможности выбора информации, текстов и заданий (то, что расходится с предпочтениями учащихся, расцениваются как неприемлемое), но с ограничениями относительно тематики и жанров текстов, количества страниц (при выборе текста для чтения и пр.), формы и жанра высказывания и др. Например, при написании сочинения студент сам выбирает жанр (эссе, фанфик, рассказ), рассказчика (персонажа, стороннего наблюдателя) и под.

5. Использование кооперативно-групповой формы работы, подразумевающей и выполнение группой своей части общего задания, и реше-

щимся сетевого мышления, а на организационном - превращением ее, образно говоря, в языковую секту. Здесь маскирование - наложение маски сетевости, являющейся совокупностью конкретных приемов и способов для «смягчения» перехода индивида из виртуальной реальности в объективную с целью беспроблемного действования в ЛДД.

${ }^{8}$ Студенты общаются вне вуза, но чаще без охвата учебно-познавательной деятельности. 
ние каждым ее членом индивидуальной задачи. С этой целью используются такие техники, как «Учимся вместе», «Обучение в команде», «Ажурная пила» и под.

Такой подход позволяет укрепить связи между учащимися, активизировать чувство ответственности, стимулировать стремление делиться материалами и результатами деятельности. Возможность же сделать что-то полезное для целой группы созвучно желанию молодежи «быть активными и конструктивными» (Łaszyn).

\section{6. ОРИЕНТАЦИЯ НА СЕТЕВОСТЬ: КОГНИТИВНЫЙ УРОВЕНЬ}

Влияние сетевости на когницию (когнитивные процессы в широком понимании) проявляется: в многозадачности индивидов; в предпочтении получать информацию в визуальной форме; в скорости ее восприятия и переработки; в ослабленности концентрации внимания на одном источнике информации; «информационный когнитивный диссонанс», возникающий из-за поступления противоречивых оценок одного и того же объекта/субъекта (Aver'yanov/Аверьянов); в переложении ответственности за сохранение сведений с себя на компьютер, что в сочетании c «эффектом Зейгарник» (забывание того, что уже было сделано) ослабляет долговременную память ${ }^{9}$.

OC на когнитивном уровне должна носить внешний характер во избежание нежелательных эффектов воздействия сетевости на обремененную клиповостью когницию.

Дело в том, что сетевость предполагает быструю смену сенсорных впечатлений, обработку информации, действование и принятие решений. Увеличение же скорости интеракций, реакций, когнитивных операций и восприятия требует простоты, т. к. у молодежи нет времени для выбирания (Łaszyn) - рассмотрения вариантов, оценки их (не)пригодности, отсеивания неприемлемых. Это укрепляет когнитивную горизонталь, подразумевающую направленность сознания на охват и обработку впечатляющего массива информационных и знаниевых данных (отсюда - становление клипового мышления). Параллельно ослабляется когнитивная вертикаль, нацеленная на углубленную обработку информации

\footnotetext{
9 Перечисленные признаки описаны в (Spitzer; Laszyn; Latoch-Zielińska; Aver’yanov/ Аверьянов; Yegorova/Егорова).
} 
и активизацию логических операций мышления. В итоге усиливается склонность индивидов к шаблонному мышлению (Yegorova/Егорова 2628), поведению, реагированию.

В силу сказанного, ОС означает, во-первых, всемерное разнообразие занятий и использование любых опций, в т. ч. противоположных. Сочетание (не)активизирующих упражнений, использование задач, заданий, форм работы разного вида (напр., стимулирующих индивидуальную когнитивную активность и совместную деятельность типа мозгового штурма) и мн. др. - все это создает впечатление высокого темпа, отвечая ожиданиям студентов. Множество же заданий, выполняемых на основании одного текста, помогают повысить концентрацию внимания учащихся на одном источнике информации.

Во-вторых, - применение маски многозадачности, т. е. постановки нескольких задач при выполнении одного задания. Например, при просмотре видеоматериала можно предложить ответить на вопросы к нему, обратить внимание на место действия, на особенности персонажа, его поведение с целью последующего описания/дискуссии. Маска многозадачности скрывает степень важности задач, позволяя беспроблемно решать наиболее значимые и малопривлекательные (в понимании учащихся).

В-третьих, - «говорение в картинках и использование языка образов» (Ditkhelm/Дитхелм 70), т. е. наложение маски визуальности на речь преподавателя для лучшего ее восприятия учащимися, предпочитающими визуальный канал получения информации. Подкрепление объяснений яркими примерами, картинками из жизни, предваренными формулой «Представьте себе...», облегчает их усвоение и осмысление.

В-четвертых, - использование информационного когнитивного диссонанса для активизации линеарного мышления, т. е. установления причинно-следственных отношений (напр., поиск причины данной оценки объекта), последствий принятия определенного решения, сравнения мнений и др., чему служат дискуссии, напр., «Аквариум», «За и против», панельные обсуждения, в т. ч. в рамках разыгрываемых фанконвенций, техники «Дерево принятия решений», «Звезда вопросов» и другие.

В-пятых, систематичная активизация усвоенных сведений в виде проверочных работ, лексико-грамматических разминок, дидактических игр типа «Домино» и под.

В-шестых, побуждение к аргументированию своего мнения, к самостоятельному поиску, обработке и усвоению сведений по какому-то вопросу, чему способствуют методы проблемного обучения. 


\section{7. ОРИЕНТАЦИЯ НА СЕТЕВОСТЬ: ЭМОЦИОНАЛЬНЫЙ УРОВЕНЬ}

Ученые отмечают у интернет-пользователей симптомы фобий и интернет-зависимости (Krupennikova \& Kurbatov/Крупенникова и Курбатов). Поскольку сетевая аддикция и интернет-синдромы среди польских студентов-русистов не изучались, отметим, что, по нашим наблюдениям, некоторые учащиеся воспринимают сведения с недоверием, поэтому они часто ищут в Сети их опровержение/подтверждение.

Повышенная эмоциональность «цифровой» молодежи, объясняется тем, что «эмоции являются сутью коммуникационных сообщений» (Yegorova/Егорова 2628). Ее нивелированию содействует «снижение уровня стресса и создание непринужденной атмосферы» (Ditkhelm/ Дитхелм 70) и рационализирование негативно воспринимающихся фактов, напр., путем раскрытия практической пригодности непонравившихся заданий.

Ученые отмечают склонность обучаемых ко всему позитивному и уверенность, что в реальности можно «скорректировать любое действие» так, как в Сети (Yegorova/Егорова 2628), напр., постоянно исправляя отметки на лучшие. Настроенность на получение только позитивных эмоций, оценок и на одобрение окружающих в совокупности с осознанием возможности перезагрузки чего угодно, обусловливает легковесное отношение к происходящему и окружению, ведущее к безответственности (Yegorova/Егорова 2628).

Недопущение ее развития требует выверения тактик ОС, призванных избежать крена в сторону излишней благоприятности при реализации главной стратегии ОС в эмотивной сфере - задать позитивный настрой на ЛДД. Равновесию способствуют, напр., проработка одинакового количества текстов юмористического, трагического и нейтрального характера; сочетание похвалы и конструктивной критики и пр. Значим учет эмоционального состояния учащегося и гибкость реагирования на него - подбодрить, успокоить или не тревожить, но не изолировать, что важно в контексте специфики межличностных отношений между «цифровыми аборигенами». 


\section{8. ОРИЕНТАЦИЯ НА СЕТЕВОСТЬ: МЕЖЛИЧНОСТНЫЙ УРОВЕНЬ}

Молодежь, завязывающая множество контактов в сетевых сообществах, переживает из-за нехватки друзей в реальной действительности (Spitzer 109-112). Налаживание контактов и сплочение языковой группы вне Сети не есть цель обучения РКИ, но задача более плотного общения студентов лицом к лицу в рамках ЛДД вполне осуществима.

Этому способствует (вне)аудиторная работа без интернета, напр., участие в дискуссионных клубах, научных кружках, секциях по интересам; подготовка и проведение мероприятий (тематических вечеров, лингвистических посиделок); выполнение творческих заданий, скажем, составить этюд, снять видеоролик к песне, визуализировать художественный текст и пр.

\section{ЗАКЛЮЧЕНИЕ}

Таким образом, ОС в целом призвана содействовать обратной адаптации индивидов к фрагменту реальной действительности (к ЛДД), установлению комфортной обстановки в нем, выравниванию дисбаланса между «цифровостью» учащихся и «аналоговостью» методики обучения иностранному языку.

Залог успеха активизации ОС - в комплексности, последовательности, систематичности, непрерывности, поэтапности ее реализации (пробное обучение, создание проекта инновации, опытное обучение, внесение коррективов в проект, выведение инновации на уровень более широкого использования) и в постоянном контроле.

Перспектива применения ОС видится в деятельностном внедрении в лингводидактическую практику и в установке на нее при создании методических разработок, учебных пособий, предметных линий учебников и многое другое. 


\section{БИБЛИОГРАФИЯ}

Aver'yanov, Gennadiy. «Matritsa OFFLINE» [Аверьянов, Геннадий. «Матрица OFFLINE»], 2015. Высшая школа методологии, www.vshm.science/blog/ggaver yanov/288. Accessed/ Доступ 30.09.2020.

Castells, Manuel. Społeczeństwo sieci. Tłum. Mirosława Marody, Kamila Pawluś, Janusz Stawiński \& Sebastian Szymański, Wydawnictwo Naukowe PWN, 2007.

Dijk van, Teun. "Badania nad dyskursem". Dyskurs jako struktura i proces, red. Teun van Dijk, tłum. Grzegorz Grochowski; red. nauk. wyd. pol. Teresa Dobrzyńska, wybór tekstów Grzegorz Grochowski, Wydawnictwo Naukowe PWN, 2001, ss. 9-44.

Ditkhelm, Gerd. Upravleniye proyektami. Tom 1: Osnovy. «Biznes-pressa», 2004 [Дитхелм, Герд. Управление проектами. Том 1: Основы. «Бизнес-пресса», 2004].

Dudel, Barbara, Marta Kowalczuk-Walędziak, Katarzyna Maria Łogwiniuk, Katarzyna Szorc i Urszula Wróblewska. Innowacje $w$ teorii i praktyce edukacyjnej (na przyktadzie województwa podlaskiego). FCTWiISP, 2014.

Filiciak, Mirosław, Michał Danielewicz, Mateusz Halawa, Paweł Mazurek, Agata Nowotny. Młodzi i media. Nowe media a uczestnictwo w kulturze. SWPS, 2010.

Gajda, Stanisław. «Szkolna edukacja językowa na tle współczesnej sytuacji lingwoedukacyjnej». Uczeń $w$ świecie języka i tekstów, red. Jolanta Nocoń \& Elżbieta Łucka-Zając, Wydawnictwo Uniwersytetu Opolskiego, 2010, ss. 19-26.

Grzmil-Tylutki, Halina. Francuska lingwistyczna teoria dyskursu. Historia. Tendencje. Perspektywy. Universitas, 2010.

Ikhsangaliyeva, Gul'nara, \& Zhanna Nurzhanova. «Innovatsionnyye trendy v metodike prepodavaniya RKI», 2014 [Ихсангалиева, Гульнара, и Жанна Нуржанова. «Инновационные тренды в методике преподавания РКИ”, 2014], pps.kaznu.kz/2/Main/FileShow2/ 14391/38/3/9/0. Accessed/Доступ 30.09.2020.

Karwatowska, Małgorzata, \& Beata Jarosz. «E-learning a blended learning w edukacji polonistycznej. Korzyści i ograniczenia». Edukacja a nowe media, red. Małgorzata Latoch- Zielińska, Iwona Morawska i Małgorzata Potent-Ambroziewicz. Wydawnictwo UMCS, 2015, ss. 49-62.

Kashina, Yelena. Traditsii $i$ innovatsii $v$ metodike prepodavaniya inostrannogo yazyka. «Univers-grupp», 2006 [Кашина, Елена. Традищии и инновации в методике преподавания иностранного языка. «Универс-групп», 2006].

Kreft, Jan. «Społeczeństwo informacyjne - podejście krytyczne». Ekonomiczne Problemy Usług, № 88,2012 , ss. 754-762.

Krupennikova, Leyla, \& Vladimir Kurbatov. «Virtual'naya lichnost': Net-myshleniye, setevoy psikhotip, Internet-fobii». Inzhenernyy vestnik Dona, № 3 (30), 2014 [Крупенникова, Лейла, и Владимир Курбатов. «Виртуальная личность: Net-мышление, сетевой психотип, Интернет-фобии”. Инженерный вестник Дона, № 3 (30), 2014].

Latoch-Zielińska, Małgorzata. «Uczeń i nauczyciel w cyfrowym świecie. Możliwości, szanse, ograniczenia». Edukacja a nowe media, red. Małgorzata Latoch-Zielińska, Iwona Morawska \& Małgorzata Potent-Ambroziewicz. Wydawnictwo UMCS, 2015, ss. 37-48.

Lysakova, Irina, redaktor. Russkiy yazyk kak inostrannyy: Metodika obucheniya russkomu yazyku. VLADOS [Лысакова, Ирина, редактор. Русский язык как иностранный: Методика обучения русскому языку. ВЛАДОС, 2004].

Łaszyn, Adam. «Szybki puls nowej generacji». Marketing Serwis, № 2, 2000, alert media.pl/bazawiedzy/czytelnia-pr/szybki-puls-nowej-generacji/. Accessed/Доступ 30.09.2020. 
Makarovska, Ol'ga. «Pokoleniye homo clipus i obucheniye russkomu yazyku kak inostrannomu: problemy i resheniya». Vestnik TGPU, № 1 (166), 2016, ss. 123-127 [Макаровска, Ольга. «Поколение homo clipus и обучение русскому языку как иностранному: проблемы и решения". Вестник ТГПУ, № 1 (166), 2016, сс. 123-127].

Melosik, Zbyszko. «Edukacja, młodzież i kultura współczesna: kilka uwag o teorii i praktyce pedagogicznej». Chowanna, vol. 46 (59), t. 1 (9), 2003, ss. 19-37.

Nosova, Snezhana. «Setevoye pokoleniye: 'Arkhitektory' ili 'gerostraty'». Vozdushnyy zamokMezhdunarodnyy zhurnal po teorii arkhitektury, vol. 19, № 32, 2014, ss. 47-65 [Носова, Снежана. «Сетевое поколение: 'Архитекторы' или 'геростраты'». Воздушный замок - Международный журнал по теории архитектуры, vol. 19, № 32, 2014, сc. 47-65 ].

Olszewska, Katarzyna. «Innowacje w oświacie». Przedsiębiorstwo we współczesnej gospodarce teoria i praktyka, vol. 2, Wydawnictwo PG, 2013, ss. 38-53.

Osipova, Ol'ga. «Realizatsiya printsipov setevogo vzaimodeystviya vusloviyakh nepreryvnogo obrazovaniya». Otechestvennoye obrazovaniye: sovremennoye sostoyaniye i perspektivy razvitiya, red. Sergey Vorovshchikov \& Ol'ga Shklyarova. MPGU, 2015, ss. 212-216 [Осипова, Ольга. «Реализация принципов сетевого взаимодействия в условиях непрерывного образования». Отечественное образование: современное состояние и перспективы развития, ред. Сергей Воровщиков и Ольга Шклярова. МПГУ, 2015, cc. 212-216].

Pfeiffer, Waldemar. Nauka języków obcych. Od praktyki do praktyki. Wagros, 2001.

Piekarczyk, Anna, \& Kazimierz Zimniewicz. Myślenie sieciowe w teorii i praktyce. Polskie Wydawnictwo Ekonomiczne, 2010.

Piekarczyk, Anna. «Myślenie sieciowe jako główna kompetencja przyszłości». Marketing i rynek, № 5, 2014, ss. 510-515.

Polak, Marcin. «Konektywizm: połącz się, aby się uczyć». Edunews.pl, 2010, edunews.pl/ badania-i-debaty/badania/1068-konektywizm-polacz-sie-aby-sie-uczyc. Accessed/Доступ 30.09.2020.

Ratajczak-Mrozek, Milena. «Istota podejścia sieciowego». Przegląd Organizacji, № 4, 2009 ss. $18-20$.

Skudrzyk, Aldona, \& Jacek Warchala. «Dyskurs edukacyjny a kompetencja interakcyjna». Polska genologia Lingwistyczna, red. Danuta Ostaszewska \& Romuald Cudak. Wydawnictwo Naukowe PWN, 2008, ss. 273-280.

Spitzer, Manfred. Cyfrowa demencja. W jaki sposób pozbawiamy rozumu siebie i swoje dzieci. Dobra Literatura, 2013.

Such, Renata. «Innowacje pedagogiczne», 2007, Chomikuj.pl, docs4.chomikuj.pl/21739 35636 , PL,0,0,Renata-Such---Innowacje-pedagogiczne.pdf. Accessed 30.09.2020.

Tapscott, Don. Cyfrowa dorostość. Jak pokolenie sieci zmienia nasz świat. Tłum. Piotr Cypryański, Wydawnictwa Akademickie i Profesjonalne, 2010.

Wilczyńska, Weronika, \& Anna Michońska-Stadnik. Metodologia badań w glottodydaktyce: Wprowadzenie. AVALON, 2010.

Yegorova, Anna. «Setevoye myshleniye: degradatsiya ili progress?». Fundamental'nyye issledovaniya, № 9-12, Izdatel'skiy Dom «Akademiya yestestvoznaniya», 2014, ss. 2626-2629 [Егорова, Анна. «Сетевое мышление: деградация или прогресс?». Фундаментальные исследования, № 9-12, Издательский Дом «Академия Естествознания», 2014, сс. 2626-2629]. 


\section{ОРИЕНТАЦИЯ НА СЕТЕВОСТЬ В ЛИНГВОДИДАКТИЧЕСКОМ ДИСКУРСЕ}

\section{Р е $з$ ю м е}

Статья посвящена рассмотрению ориентации на сетевость как дидактической инновации, призванной модернизировать процесс (об)учения иностранному языку. Ориентация на сетевость, как и клиповое мышление, является одной из характерных черт нового поколения студентов, которых называют «цифровыми аборигенами». В статье дефинируются понятия лингводидактического дискурса и ориентации на сетевость. В ней также перечисляются основные элементы ориентации на сетевость. Обращается внимание на то, что ориентация на сетевость как инновация основывается на внесении изменений в организацию и процесс обучения с целью модернизации лингводидактического дискурса.

Ключевые слова: лингводидактически дискурс; нововведения в глоттодидактике; цифровые аборигены; ориентация на сетевость; техника маскировки

\section{ZWROT KU SIECIOWOŚCI \\ W DYSKURSIE GLOTTODYDAKTYCZNYM}

Streszczenie

Artykuł poświęcono zwrotowi ku sieciowości jako innowacji dydaktycznej modernizującej proces nauczania - uczenia się języka obcego. Sieciowość jak i myślenie klipowe należy do jednej z cech nowego pokolenia młodzieży określanego mianem „,cyfrowych tubylców”. W artykule zdefiniowano pojęcie dyskursu glottodydaktycznego i pojęcie sieciowości. Wyszczególniono podstawowe elementy sieciowości. Zwrócono uwagę, że zwrot ku sieciowości jako innowacja polega na wprowadzeniu zmian dotyczących organizacji i sposobów działania w celu unowocześniania dyskursu glottodydaktycznego.

Slowa kluczowe: dyskurs glottodydaktyczny; innowacje w glottodydaktyce; „,cyfrowi tubylcy”; zwrot ku sieciowości; technika maskowania.

\section{NETWORK ORIENTATION \\ IN THE DISCOURSE OF THE DIDACTICS OF TEACHING}

\section{Su m mary}

This article is devoted to the study of network orientation as an innovative method of teaching a foreign language, which is used in the didactics of teaching. Network orientation and clip thinking are characteristic features of the new generation of students who are referred to as "digital natives". This article provides a definition of the discourse in the didactics of teaching and network orientation. It also enumerates the constitutive elements of network orientation. The article draws attention to the fact that network orientation as an innovation in the discourse of the didactics of teaching is based on introducing certain changes in the organisation and act of teaching in order to modernise glottodidactics discourse.

Key words: discourse of the didactics of teaching; innovations in the didactics of teaching; digital natives; network orientation; disguise technique. 